\title{
A SCATTERING EXPERIMENT USING DIGITIZED DISCHARGE PLANES*
}

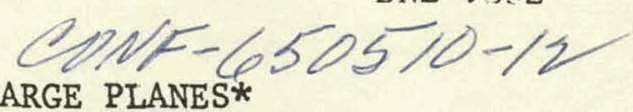

E. Bleser, E. Anderson, G. B. Collins, T. Fujii, S. Heller, J. Menes, F. Turkot

Brookhaven National Laboratory, Upton, New York and

R. Carrigan, R. Edelstein, N. C. Hien, T. McMahon, I. Nadelhaft

Carnegie Institute of Technology, Pittsburgh, Pennsylvania

and

Yu. D. Prokoshkin

Institute of High Energy Physics, Serpukhov, Moscow Region, U.S.S.R.

The preliminary experience at the A.G.S. of an experiment using wire chambers with a magnetic core read out connected on-1ine to a PDP- 6 computer has been very encouraging. The wire chamber system at Brookhaven has been under development for two years and has been reported in several publications by W. Higinbotham and J. Fischer. (1)

The experiment is designed to study inelastic proton-proton scattering (2) over a wide range of angles and incident energies. It measures the momentum spectrum of the scattered protons using a spectrometer which has a solid angle of $10^{-4}$ stearadians, a momentum bite of $20 \%$, and a momentum resolution of better than $0.5 \%$. The layout is shown in Fig. 1. A proton beam is incident on a liquid hydrogen target. The scattering angle is measured by the first leg of the spectrometer. There are four X (horizontal). planes and $4 \mathrm{Y}$ (vertical) planes to determine the horizontal and vertical projections of the particle's path. (See T. Fujii et al., (3) for a discussion of the benefits of using 4 planes to overdetermine a straight line.) A second set of $4 \mathrm{X}$-planes after the bending magnet determines the particle's momentum. A large threshold Cerenkov counter separates pions and protons. The system is triggered on scintillation counters S1, S2, S3, and the Cerenkov. Each time the planes are fired the cores which have been flipped are read out into a 4000 word buffer memory. The buffer memory stores events 


\section{DISCLAIMER}

This report was prepared as an account of work sponsored by an agency of the United States Government. Neither the United States Government nor any agency Thereof, nor any of their employees, makes any warranty, express or implied, or assumes any legal liability or responsibility for the accuracy, completeness, or usefulness of any information, apparatus, product, or process disclosed, or represents that its use would not infringe privately owned rights. Reference herein to any specific commercial product, process, or service by trade name, trademark, manufacturer, or otherwise does not necessarily constitute or imply its endorsement, recommendation, or favoring by the United States Government or any agency thereof. The views and opinions of authors expressed herein do not necessarily state or reflect those of the United States Government or any agency thereof. 


\section{DISCLAIMER}

Portions of this document may be illegible in electronic image products. Images are produced from the best available original document. 


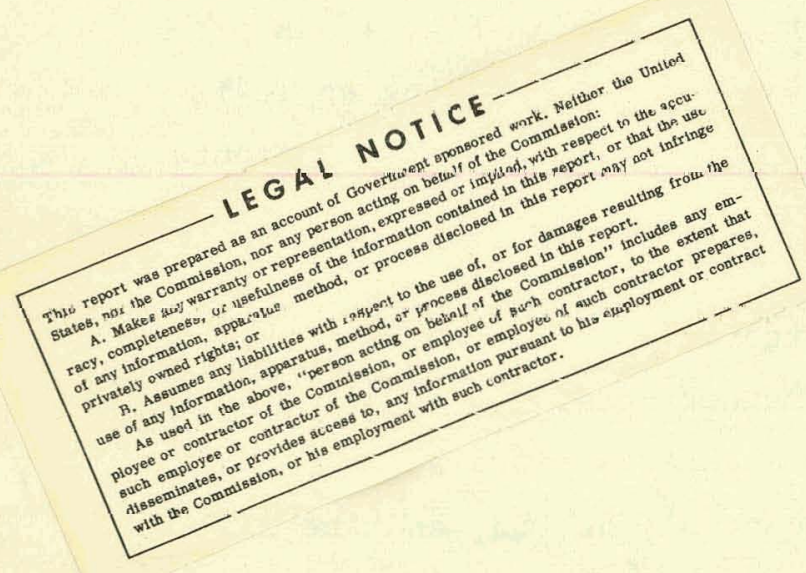


for the $300 \mathrm{~ms}$ duration of the A.G.S. pulse and is then read into the PDP- 6 computer at the end of the spill. In the two seconds before the next A.G.S. pulse the computer calculates the scattering angles and momenta of the scattered protons. Details of the computer analysis are given by Fujii et al.

\section{PROPERTIES OF THE SYSTEM:}

The most important property of the system is the rate at which it can take data. This is determined by the rate at which the planes can be fired, discussed in detail by Fischer. (1) In order to ensure long-life and trouble-free operation the system has been run conservatively, triggered only every $1.7 \mathrm{~ms}$, giving 150 events per A.G.S. pulse.

The spatial resolution of these planes is determined by the wire spacing, which is 0.050". Figure 2, a plot of the root-mean-square deviation of the sparks from the best fit straight line shows that a spark will be within one half of a wire spacing of the fitted line. Since each segment is $360^{\prime \prime}$ long the angle of a particle's trajectory can be determined to an accuracy of $0.2 \mathrm{mr}$. The angular resolution of the system was measured by comparing the direction of a particle in the first segment with its direction in the second segment with the spectrometer magnets turned off. The distribution of the differences had a full width at half-maximum of $0.3 \mathrm{mr}$, which is $\sqrt{2} \times 0.2 \mathrm{mr}$ as expected.

The momentum resolution of the spectrometer is calculated at 30 $\mathrm{BeV} / \mathrm{c}$ from the angular resolution to be $0.4 \%$. The best measurement gives a full width of $0.56 \%$ for a proton beam whose momentum spread of at least $0.25 \%$ must be folded into the spectrometer: resolution. At $10 \mathrm{BeV} / \mathrm{c}$ the width of the momentum resolution is due equally to the spatial resolution and to the multiple scattering in the planes - which contain 2 mills of copper. Since the analyzing angle is 3 times greater, the calculated momentum resolution at $10 \mathrm{BeV} / \mathrm{c}$ is $0.25 \%$.

The overall efficiency of the 12 plane spectrometer for determining a good track depends on the flux of particles through the spectrometer and is shown in Fig. 3. This result is very encouraging for the efficiency is still as high as $50 \%$ even when there is a flux of 100,000 particles per 
pulse through the planes. The Inefficiency is due to multiple tracks in the planes, events of this sort being rejected by the present analysis program, or to two different particles passing through the segment at the same time - one particle sparking in two of the planes and the other sparking in the other 2 planes - resulting in a bad fit. Events of this sort give the tail on the distribution in Fig. 2. The resolving time of the planes is about one microsecond and is so long because of the signal transit times involved in a system spread over 100'.

Figure 4 shows a momentum spectrum obtained with an incomplete set up. This was obtained in seven minutes at one setting of the spectrometer and demonstrates the $20 \%$ momentum bite. Typical data taken during a seven minute beam analysis run is shown in Fig. 5.

Conclusions from this preliminary work are that the planes are quite reliable and give good results. The complete system has been used for one month and has experienced no failures, no broken wires, no hot spots and no bad cores. The spectrometer was located in a beam cave, closed when the beam was on, but even without close monitoring everything ran smoothly. In one month the 12 planes were fired one million times each and no deterioration of the planes was observed. In one day 40 separate runs were made and one half million events were taken and analyzed on line. 


\section{WIRE PLANE SIZES}

\begin{tabular}{|c|c|c|c|}
\hline Plane & Width & Helght & $\begin{array}{c}\text { Distance from } \\
\mathrm{H}_{2} \text { Target }\end{array}$ \\
\hline $\begin{array}{l}X 1 \\
Y 1\end{array}$ & $3.2^{\prime \prime}$ & $3.2^{\prime \prime}$ & $156^{\prime \prime}$ \\
\hline $\begin{array}{l}\mathrm{X} 2 \\
\mathrm{Y} 2\end{array}$ & $4.8^{\prime \prime}$ & $3.2^{\prime \prime}$ & $276^{\prime \prime}$ \\
\hline $\begin{array}{l}X 3 \\
Y 3\end{array}$ & $6.4^{\prime \prime}$ & $4.8^{\prime \prime}$ & $396^{\prime \prime}$ \\
\hline $\begin{array}{l}\mathrm{X} 4 \\
\mathrm{Y} 4\end{array}$ & 9.611 & $4.8^{\prime \prime}$ & $516^{\prime \prime}$ \\
\hline$\times 5-8$ & $17.6^{\prime \prime}$ & $8.0^{\prime \prime}$ & $\begin{array}{r}797^{\prime \prime}, 917^{\prime \prime}, \\
1037^{\prime \prime}, 1157^{\prime \prime}\end{array}$ \\
\hline
\end{tabular}

20 wires to the inch. 


\section{References:}

1. W. A. Higinbotham, a paper submitted to this conference.

J. Fischer, a paper submitted to this conference.

J. Fischer, G. B. Collins, W. A. Higinbotham, Proc. Internat. Symp. on Nuclear Electronics, Paris, p. 57, Nov. 1963.

G. B. Collins, J. Fischer, W. A. Higinbotham, CERN 64-30, 117, June 1964.

2. G. B. Chadwick, G. B. Collins, P. J. Duke, T. Fujii, N. C. Hien, M。A.R. Kemp, and F. Turkot, Phys. Rev. 128, 1823 (1962); G. Cocconi, E. Lillethun, J. P. Scanlon, C. A. Stahlbrandt, C. C. Ting, J. Walters, and A. M. Wethere11, Phys. Letters 8,134 (1964).

3. T. Fujii, a paper submitted to this conference. 


\section{Figure Captions:}

Fig. 1. Schematic layout of proton scattering experiment using 12 wire planes.

Fig. 2. RMS deviation of sparks from best straight line

$$
\zeta=\left\{\left(\zeta_{1}^{2}+\zeta_{2}^{2}+\zeta_{3}^{2}+\zeta_{4}^{2}\right) / 4\right\}^{\frac{3}{2}}
$$

Fig. 3. Total efficlency of 12-plane spectrometer versus number of particles incident. per msec.

$$
\begin{aligned}
& E=\text { Total good events } / \text { Total input events } \\
& \lambda=\text { Number of }(S 1, \mathrm{~s} 2) \text { coincidences per millisecond } \\
& E=94 \mathrm{e}^{-2.1 \times 10^{-3} \lambda}
\end{aligned}
$$

Fig. 4. Momentum spectrum showing the elastic peak and a broad isobar bump. The momentum resolution is crude since the bending angle was small $\left(2^{\circ}\right.$ instead of $\left.12^{\circ}\right)$.

Fig. 5. Results of a 7 minute beam analysis run. The figure shows the angular divergence of the incident proton beam and the corresponding wire maps for. $\mathrm{planes} X 1$ and $X 8$ which are separated by $1,000 "$. A wire map is a record of the number of times each wire sparks. The beam spike stands out clearly over a flat background. This background is due to real particles triggering the system since it drops sharply to zero at the edge of the trigger counter which is at $0.75^{\prime \prime}$ for plane $\mathrm{Xl}$. 
SCHEMATIC LAYOUT PROTON SCATTERING EXPERIMENT

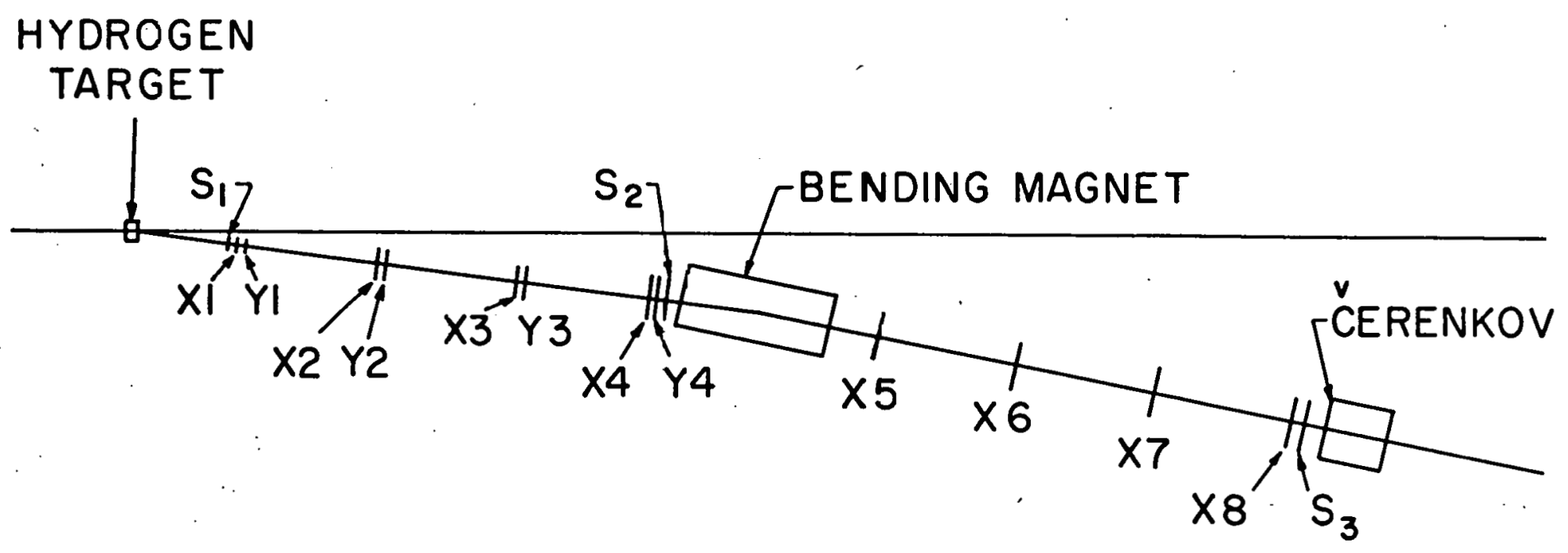

Figure I 
RMS DEVIATION OF SPARKS FROM BEST STRE:.:

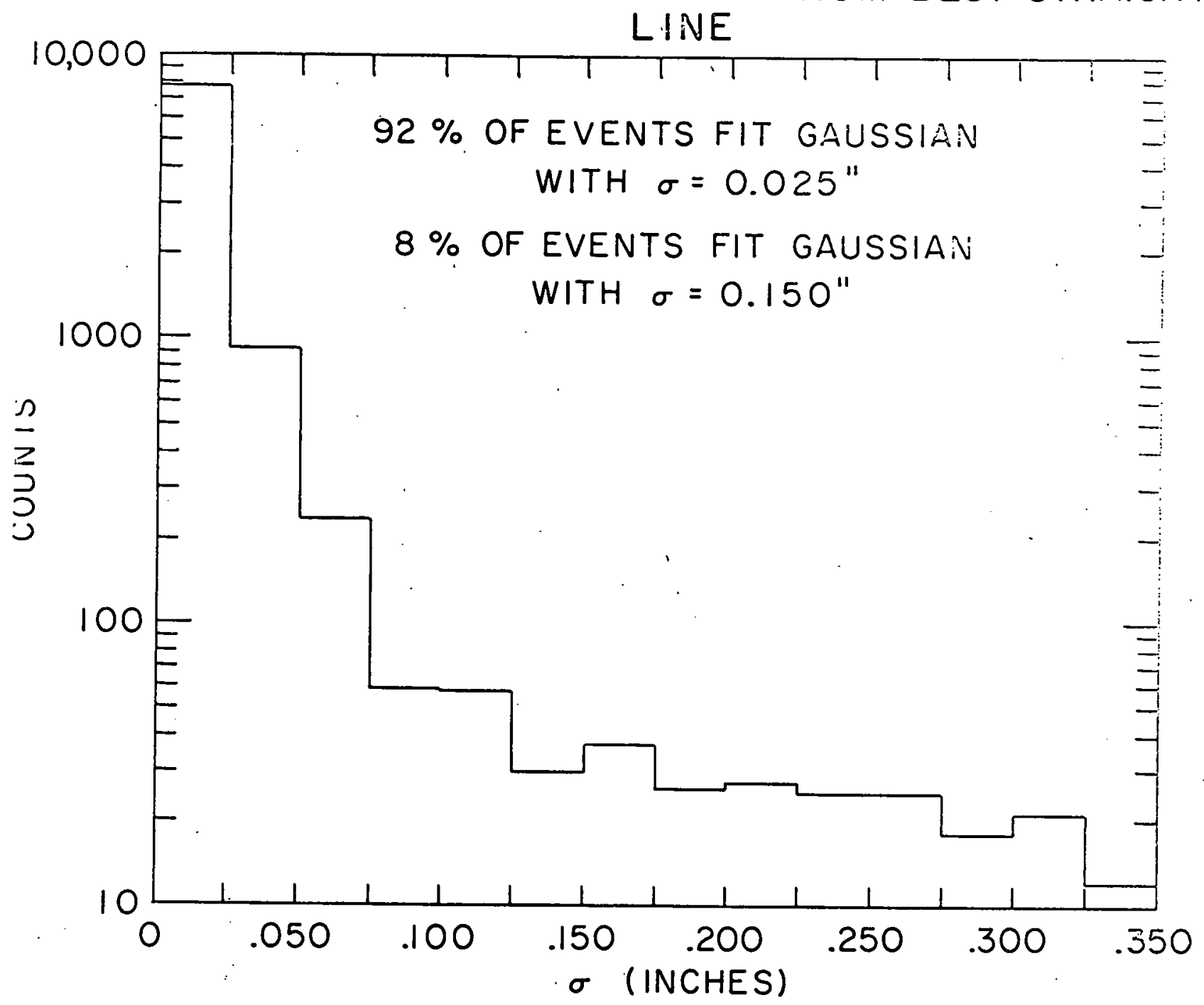

Figure 2 


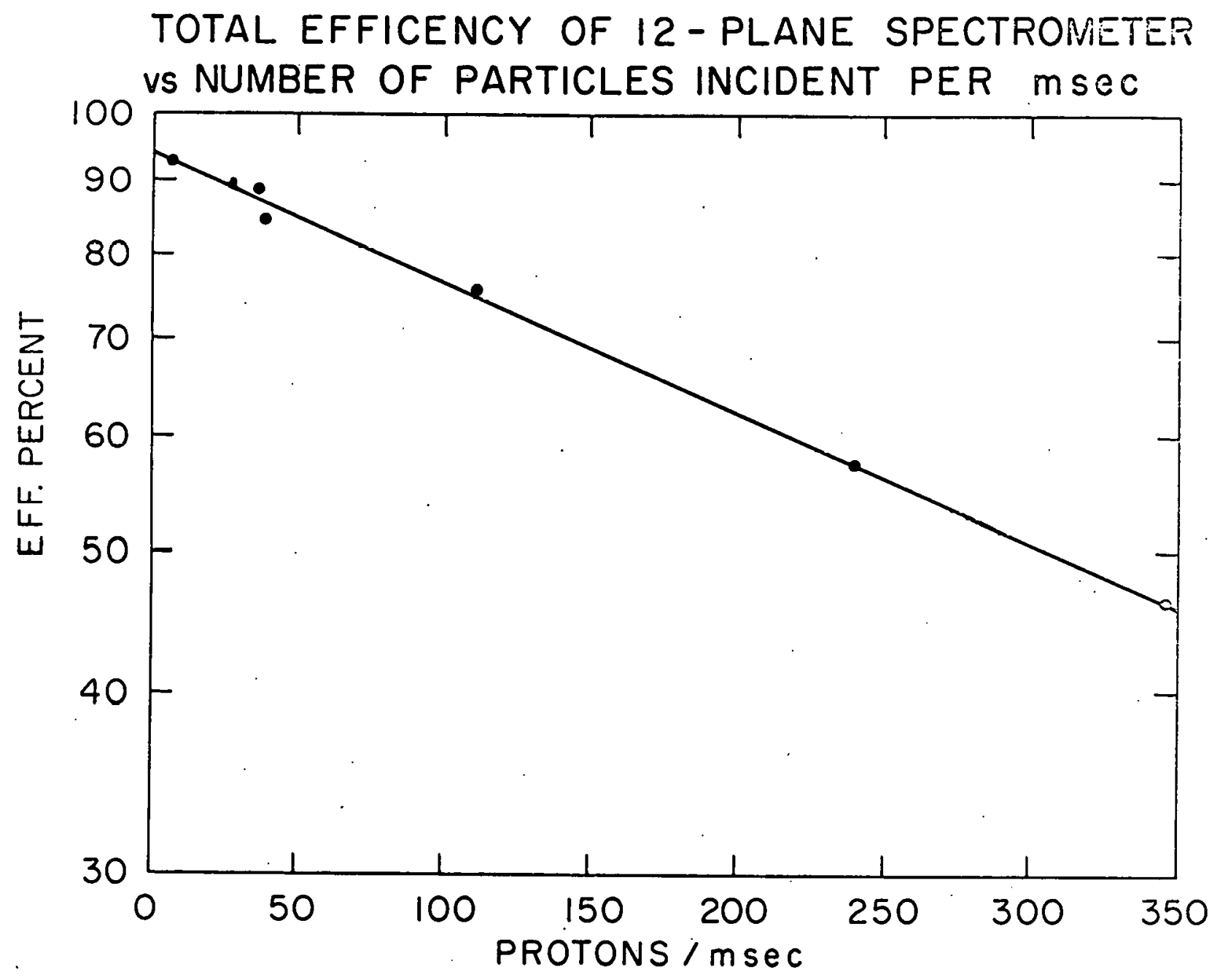

Figure 3 


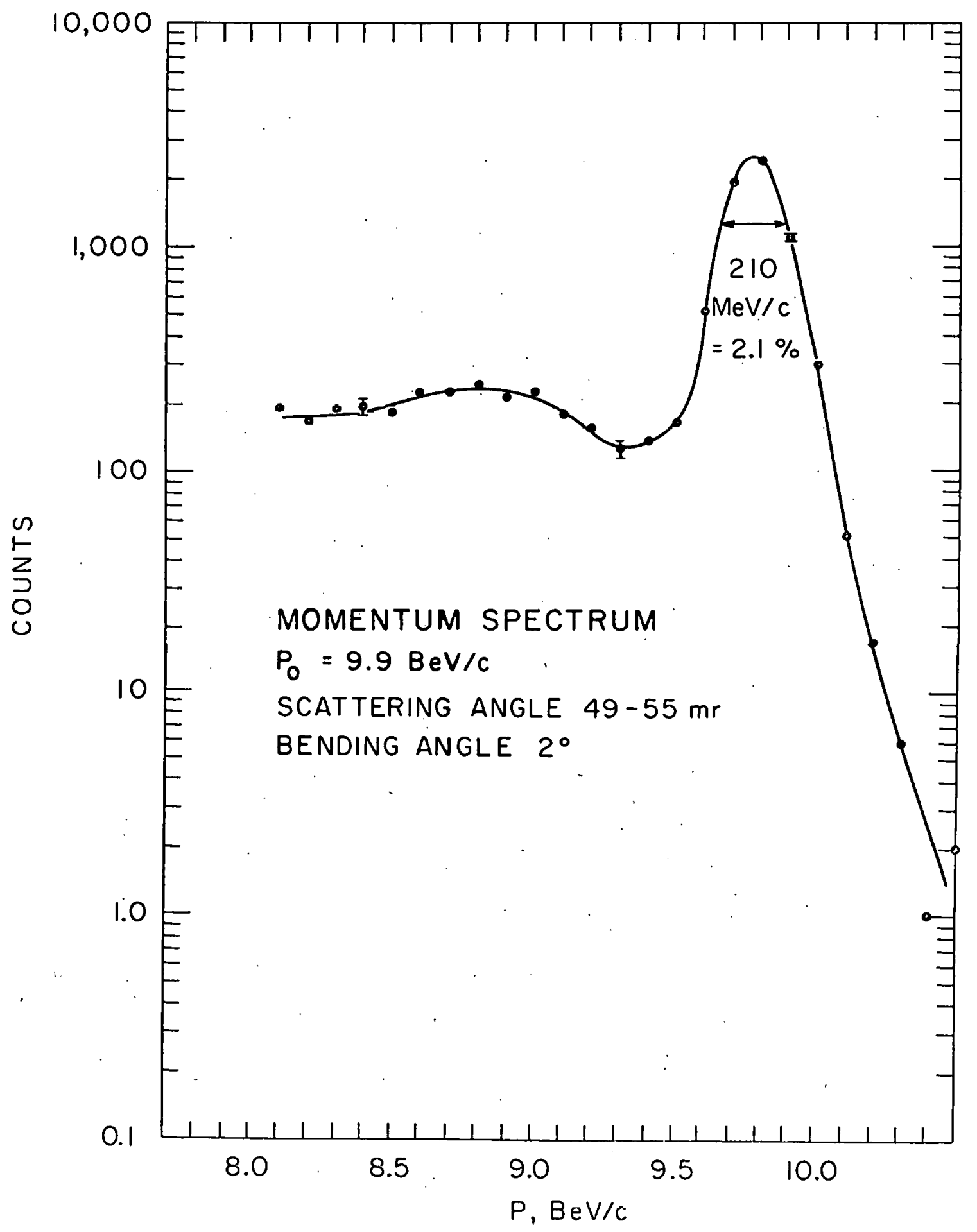

Figure 4 


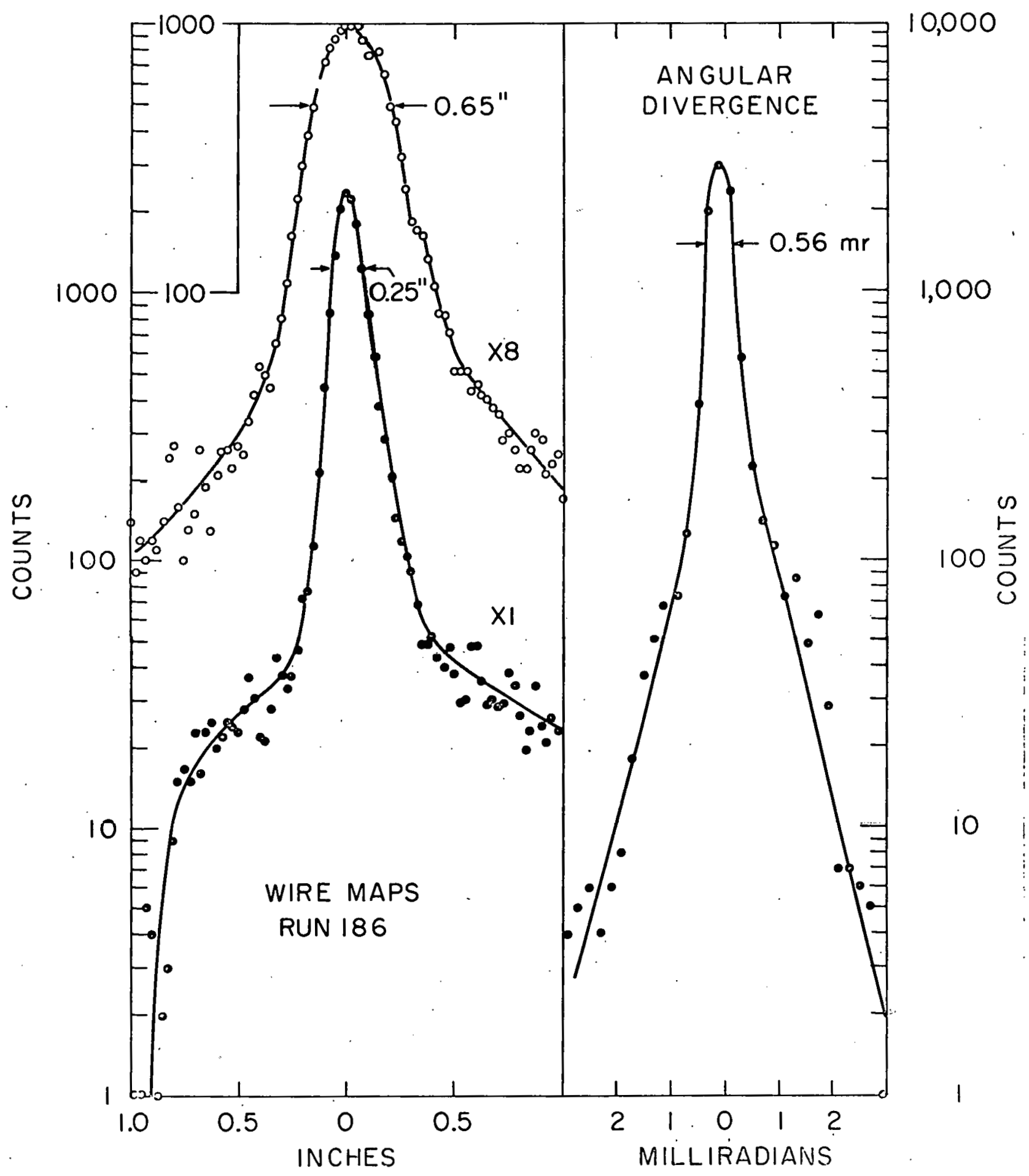

Figure 5 